\title{
Use of instrumented charpy testing on the fracture toughness characterization of metallic materials
}

\author{
Luiz Carlos Pereira ${ }^{1 *}$ (1) \\ Juan Carlos Garcia de Blas ${ }^{2}$ \\ Sandro Griza ${ }^{2}$ \\ Fathi Aref Ibrahim Darwish ${ }^{2}$
}

\begin{abstract}
The Charpy test has been used for over a hundred years as an important tool in the qualification of materials in engineering projects and in the development of new metal alloys. The instrumentation of the Charpy test allowed its use in determining the dynamic fracture toughness parameters $\left(\mathrm{K}_{\mathrm{Id}}, \mathrm{J}_{\mathrm{Id}}\right)$, and thus the verification of the effects of temperature and loading rate on the performance of metallic materials. The small sample sizes, ease in preparing these samples and execution the tests have been guaranteeing their use in the various areas of engineering. Prof. Telmo R. Strohaecker was one of the pioneers in the use of the Instrumented Charpy test in the country in determining parameters of the dynamic fracture mechanics for the characterization of the fracture toughness of high-strength low-alloy steels.
\end{abstract}

Keywords: Instrumented Charpy test; Dynamic Fracture Toughness; Ductile-brittle transition.

\section{Introduction}

The use of metallic materials in engineering projects led to the need to characterize the requirements for mechanical strength to establish the maximum design stress values, and how they behave under different load modes (static, dynamic and cyclic) and environmental conditions (temperature). This information became imperative with the occurrence of failures in service of the railway equipment, mainly on the rails and axles during the $19^{\text {th }}$ century. The fractures generally occurred without any prior warning, that is, there was no visible indication of the presence of plastic deformation, which would be indicative of localized overload. This resulted in catastrophic accidents, with serious economic losses resulting from the stoppage of services, and in some cases, injuries and deaths.

From the analysis of these accidents, the following facts draw attention: (i) the stress conditions were below the design critical values; (ii) in general, the components were subjected to cyclic loading; (iii) the fracture surfaces revealed the starting point and crack propagation, until reaching a critical crack size that resulted in the fracture of the component in a catastrophic way. This set of evidence resulted in a new type of fracture of metallic materials: Fatigue. Another important characteristic observed in metallic materials, with emphasis on low carbon steels (bcc-ferrite), refers to its change in behavior, becoming brittle (low fracture energy) when subjected to low temperatures and under dynamic loading (impact) [1].

\section{Some historical data from the impact test}

In the characterization of those metallic materials, considering the effects of temperature, the dynamic loading mode and the need to include the notch / crack in the samples, it was necessary to develop a new mechanical test that met these requirements. Records in the history of mechanical impact tests [2] indicate that the first pendulum impact tests on the characterization of the mechanical properties of metallic materials were made by Russel in 1898 (reprint in ASTM STP 1380) [3].

According to the bibliographic notes on the evolution of the impact test [4], in 1901, G. Charpy made a communication in congress and published a technical paper at the Journal of the Soc. Ing. Civ. de Francais (reprint in ASTM STP 1380) [5] with his considerations on the need to perform dynamic tests on metallic materials, considering the differences in mechanical behavior of these materials under static and dynamic (pendulum) load conditions [5]. In the dynamic test the measurement of fracture energy is obtained from the difference between the initial and final height of the pendulum after fracturing the sample by bending. In

${ }^{1}$ Programa de Engenharia Metalúrgica e de Materiais - PEMM, Instituto Alberto Luiz Coimbra de Pós-graduação e Pesquisa de Engenharia COPPE, Universidade Federal do Rio de Janeiro - UFRJ, Rio de Janeiro, RJ, Brasil.

${ }^{2}$ Programa de Pós-graduação em Ciência e Engenharia dos Materiais, Universidade Federal de Sergipe, São Cristóvão, SE, Brasil.

${ }^{3}$ Programa de Pós-graduação em Engenharia Civil, Universidade Federal Fluminense - UFF, Centro Tecnológico, Niterói, RJ, Brasil.

*Corresponding author:lula@metalmat.ufrj.br; lula.lcpereira@gmail.com

2176-1523 (C) 2021. Pereira et al. Published by ABM. This is an Open Access article distributed under the terms of the Creative Commons Attribution License, which permits unrestricted use, distribution, and reproduction in any medium, provided the original work is properly cited. 
these analyzes, the effects of the notch in the samples are highlighted, and mainly, the radius of the tip. The detailed description of the tests reveals the various issues still pending at that time: pendulum speed, hammer geometry, and how these factors could influence material performance results. A prominent topic was how to include dynamic testing for the classification of materials in engineering projects [5]. In this article, when referring to the work presented by Russel [3], Charpy confers the primacy of dynamic tests with pendulum on the American researcher. The identification of this dynamic pendulum test as a "Charpy test" is due to the active participation of this researcher in congresses and in the commissions of technical associations. In 1905, the first references to the dynamic test with pendulum as "Charpy test" and "Charpy method" are recorded in the literature [4].

In the early 1900's, impact tests (Drop Weight, Pendulum and Flywheel) are diversified and follow discussions regarding their testing standards, including: specimen dimensions, notch type (U, V, keyhole), notch size and tip radius, initial impact speed, how to ensure the impact energy necessary for fracture, but minimizing the effect of vibrations, energy losses due to contact deformation of the sample, friction of moving parts, and how to measure the amount of energy absorbed by the sample in the fracture. It was also discussed if the results were reproducible, what range of results would be acceptable, and mainly, how to use these results in engineering projects. In 1933, the first impact test procedure was published by the American Society for Testing and Materials, ASTM E-23-33T [4], which has been undergoing successive updates [6].

The Charpy test has its use consolidated in engineering through the ductile - brittle transition curve with temperature, obtained from the values of fracture energy (Ecv) or appearance in fracture modes (measured in percentage of fibrous or cleavage fracture area on the surface of fractured samples - FA\%), for each test temperature (T). These curves resulted in the following parameters: ductile-brittle transition temperature (DBTT) associated with a specific energy value, Lower Shelf Energy (brittle fracture) and Upper Shelf Energy (ductile fracture) $[7,8]$.

One of the most significant events for the adoption of impact tests and the Charpy transition curve in the steel specification standards and manufacturing processes is due to the fracture events on the "Liberty" ships (American project) that occurred during the II World War [2]. More than $20 \%$ of these ships had some kind of fracture that required repairs. The damage ranged from minor damage to fractures so severe that they led to the total loss of the ships. The research on that fracture phenomenon demonstrated the effectiveness of the impact test in revealing the ductile-brittle transition of the steels used in the manufacture of ships, and thus the need to include the Charpy test in the construction standards of naval structures.

\section{Use of fracture mechanics on the materials characterization and engineering projects}

In the following decades, fracture concepts based on the principles of Linear Elastic Fracture Mechanics (G, K), restricted to fracture situations in which there is no plastic deformation (or to a very small extent - small-scale yielding), and gained importance. From the $\mathrm{G}_{\mathrm{Ic}} / \mathrm{K}_{\mathrm{Ic}}$ parameters it was possible to determine under what conditions a solid containing a crack, submitted to tensile stress, reaches its fracture condition [9-11]. In situations where there is some plastic deformation at the crack tip in the fracture process, an approach based on the concepts of Elasto Plastic Fracture Mechanics is necessary, using the parameters J Integral and CTOD. In this case, the significant events in the fracture process will be those associated with local stress and strain fields at crack tip (J Integral) and crack tip opening displacement (CTOD) [12-15]. In the "process zone" the stable crack growth occurs in a succession of events: rounding of the crack tip (by shear), formation of microcavity in front of it, followed by the growth of this microcavity and its coalescence with the tip of the crack. The stable crack growth can be characterized by its "Resistance Curve" (R curves), presented by $J_{R} \cdot(\Delta a)$ or $\delta_{R} \cdot(\Delta a)$. From the resistance curve and the material's mechanical properties (yield and tensile strength), it is possible to identify the crack initiation $\left(\mathrm{J}_{\mathrm{IC}} / \delta_{\mathrm{IC}}\right)$ and grow events. Thus, under static loading conditions, it is possible to analytically configure all stages of the fracture process of structures containing cracks [16].

The use of those parameters of fracture mechanics in the qualification and quality control of metallic structures are contained in specifications such as: SINTAP [17,18], BS: 7910 [19] and API-5L [20].

\subsection{Instrumented impact Charpy Test}

The approach to fracture process under dynamic loading conditions has always been associated with the measurement of the total amount of energy absorbed in the fracture process. A better understanding of the dynamic fracture process would be possible through instrumentation of the impact pendulum. From the record of the signal of load $(\mathrm{P})$ - time $(\mathrm{t})$ or load $(\mathrm{P})$ - deflection $(\Delta)$ it is possible to measure the absorbed energies associated with fracture events: initiation, stable growth, unstable growth and the final rupture of the sample, considering that this energy is associated with the area under the curves P-t or P- $\Delta$.

There are indications that the first instrumented impact tester was built by the German company Werkstoffprüfmaschine Leipzig in the 1950's [2]. A piezoelectric sensor was used to measure the impact load. A "flag" attached to the pendulum triggered a photocell, which produced an electrical signal to start recording the impact load on an oscilloscope. In the years that followed, various equipment with operating concepts similar to this one were manufactured in different 
countries [4]. In turn, several committees were involved in discussions with the objective of establishing the procedures to validate the results of impact tests by instrumented pendulum. This resulted in the ISO 14556 [21], ASTM E2298 [22] and ASTM E23 [6]. With the use of samples with fatigue cracks in Charpy Instrumented tests, it is possible to estimate the dynamic fracture toughness $\left(\mathrm{K}_{\mathrm{Id}}\right)[23,24]$. Therefore, fracture mechanics testing procedures based on Charpy instrumentation have an increasing acceptance in the characterization of materials, whether in teaching, research \& development [25-27], as well as in industrial use in material selection, quality control or surveillance programs, with emphasis on the areas of nuclear energy [28-37] and oil \& gas [38-41].

\section{The use of instrumented charpy test in Brazil}

Records on the use of Charpy Instrumented equipment in Brazil indicate that in the 1970's it was installed at DCMM - PUC / Rio under the supervision of Prof. Fathi A. I. Darwish a Tinius Olsen equipment (406 J) with the instrumented dynamic load cell model Dynatup 74, and with signal processing and recording Dynatup Model 500 System: Dynamic Respond Modules - DRM, Velocometer Respond Modules - VRM and Tektronix 5103N / D13 oscilloscope. These signals ("load-time" and "energy-time"), retained on the oscilloscope screen, allow photographic recording after the test (Figure 1). At the end of the 1970's, an equipment similar to that of DCMM / PUC-Rio was installed at the Electric Energy Research Center - CEPEL (Rio de Janeiro), with the advantage of having a device with variable initial height for the hammer, and thus the control of the velocity $V_{o}$ and the initial impact energy $E_{0}$.

The DCMM equipment was used by the author's (Pereira) under the supervision of Prof. Fathi Darwish in impact tests as an integral part of her undergraduate research work and graduate research for M.Sc. degree in the years 1977-1981 [42,43].

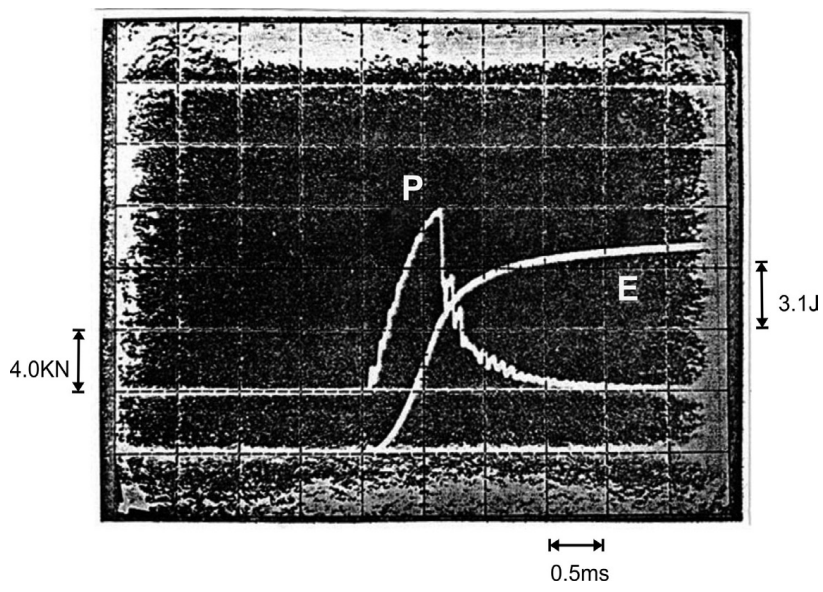

Figure 1. Instrumented Charpy test: Load (P-t) and Energy (E-t) curves.
At the same time, Prof. Telmo R. Strohaecker was developing his research for the M.Sc's degree at PPGE3M/ UFRGS under the academic guidance of prof. W. Dejonghe. Independently and without previous contact with the PUC-Rio research group, he addressed in his work a subject related to that developed by Pereira \& Darwish, including the assessment of dynamic fracture toughness of the HSLA and under similar heat treatment conditions [44]. At the PPGE3M/UFRGS a Charpy Instrumented (WPM-Leipzing) was installed, which allowed the registration of the load displacement curve. However, since it was a first generation equipment, the records of impact loads were presented on an oscilloscope with limited resources, which made difficult to record the load signal in the tests. As a result, Strohaecker came to DCMM-PUC/Rio to carry out the dynamic fracture toughness tests there. During his tests, a methodology was developed that allowed the decrease of the initial pendulum height $\left(\mathrm{h}_{\mathrm{o}}\right)$, and thus a lower initial impact velocity / energy and consequent control of oscillations [45,46].

In both works, in addition to assessing the dynamic fracture toughness of these steels at different conditions of quenching and tempering, it was necessary to understand the effect of austenitic grain size (function of austenitizing temperature) and the radius of the tip notch ( $\rho$ ) in the absorbed energy and fracture toughness properties with instrumented Charpy test $[43,44]$.

\section{Energy and fracture toughness from instrumented charpy test: crack tip effect}

The main issues that arose at that time regarding the fracture toughness of this class of steels (HSLA) subjected to quenching and tempering heat treatments, were related to the following results: in fracture toughness tests $\left(\mathrm{K}_{\mathrm{Ic}}\right.$ or $\left.\mathrm{K}_{\mathrm{Id}}\right)$, with specimens with fatigue crack $(\rho \approx 0)[15]$, the fracture toughness increase with the increase in the austenitization temperature, and therefore with the austenite grain growth [47]. However, when the toughness is evaluated using the Charpy test, with specimens with conventional tip notch $(\rho=0.25 \mathrm{~mm})$ or larger radius, the toughness value measured by impact fracture energy $\left(\mathrm{E}_{\mathrm{cv}}\right)$ decreases with the increase of grain size of austenite, as shown in the graphs in Figure 2. These results constitute an apparent paradox, since both are parameters related to the toughness of the material, therefore, they should follow the same trend $[48,49]$.

These researches are connected by addressing the relationship between fracture toughness values and the microstructural characteristics of polycrystalline metallic materials. Therefore, it is necessary to have a better understanding of the stress and strain fields in front of the fatigue crack or notch, which are associated with the radius of the crack tip $(\rho)$. In this region, the fracture micromechanisms (brittle or ductile) will act when a critical localized fracture stress value $\left(\sigma_{\mathrm{f}}{ }^{*}\right)$ or critical localized fracture strain $\left(\varepsilon_{\mathrm{f}}{ }^{*}\right)$ is reached, respectively. In addition, it 


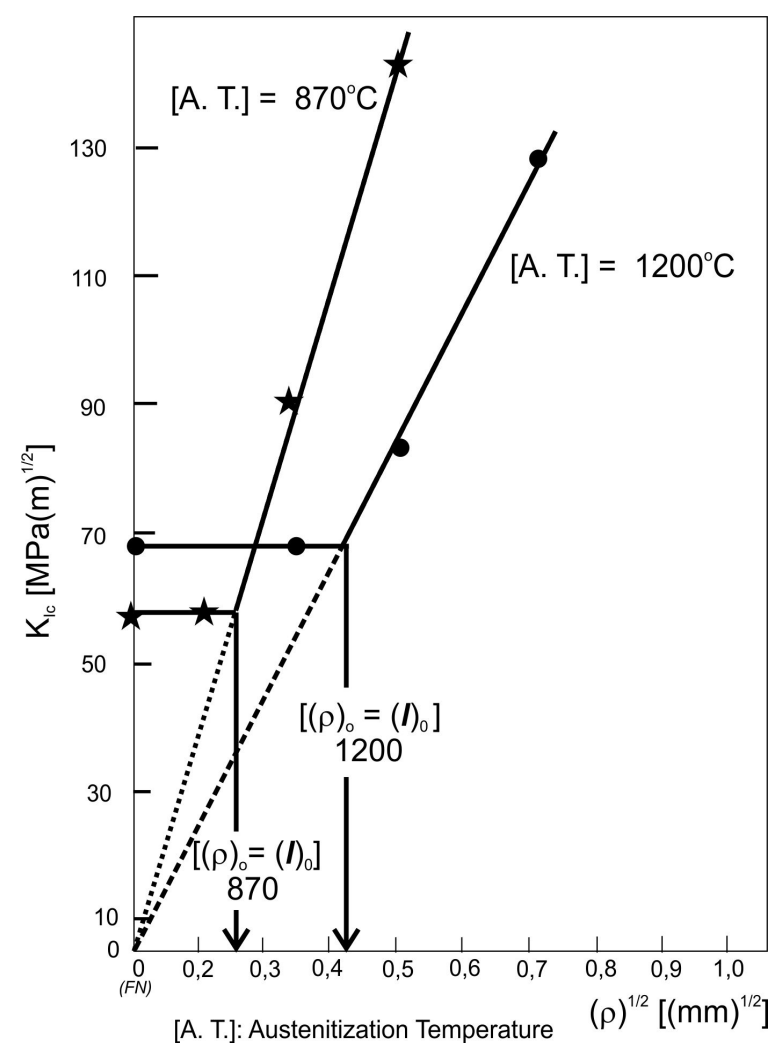

Figure 2. Fracture toughness $\mathrm{K}$ values for different crack notch radius for AISI 4140 Quenched steel - A.T. = Austenitization Temperature [48].

is necessary to include in this "process zone" for fracture a parameter of the microstructure associated with the fracture initiation, referred to as the "characteristic distance" $\left(l_{0}^{*}\right)$, which is associated with the grain size, distance between carbides and inclusions. These approaches are present in the literature in the form of "[...] microscopic models of fracture processes [...]" [48-50].

Another topic of interest related to the occurrence of embrittlement in this class of steels when subjected to quenching and tempering (Q\&T) at temperatures close to $350^{\circ} \mathrm{C}$, a specific form of embrittlement high strength steels, addressed in the literature as Tempered Martensite Embrittlement (TME). These questions indicated the need to correlate the toughness values and their microstructures with the fracture micromechanisms that act in each case, and this theme has been the subject of studies in the following decades [51-55].

\section{Microscopic fracture mechanics models}

For the cleavage fracture, there is the model proposed by Ritchie et al. (RKR model) [55], which was developed from the work carried out by Tetelman and Knott [56]. A broader approach to this model is presented by Thompson and Knott [57] and a verification of this process, using statistical criteria, was proposed by Evans [58]. A current discussion on models related to the micromechanism of cleavage fracture is presented by Chen and Cao [59]. As for the micromechanisms of brittle intergranular fracture, an in-depth approach is presented by Pugh [60]. With regard to micromechanism of ductile fracture model, the comprehensive approaches carried out by Thomason [61] and Ritchie and Thompson [16] stand out.

A detailed approach on micromechanisms of fracture in metallic materials (steel and aluminum alloys) was carried out by Graça [62]. The influence of the mechanical properties of the materials and the local stress and strain fields, associated to the different values of the radius of the root of the notch ( $\rho)$, were related to the processes for fracture. The fracture (cleavage or ductile) have been extensively documented through metallographic and fractographic analyzes of Charpy samples submitted to the instrumented impact tests, as well as the tests in slow and interrupted bending. It was possible to establish correlations between the fracture toughness values and the dominant fracture micromechanisms in each case. Another comprehensive review of fracture in the ductile-brittle transition in steels is presented by Pineau [63]. It addresses the microscopic models of brittle and ductile fractures, based on metallographic and fractographic analyzes in the fracture initiation and propagation stages.

\section{Characteristics curves of the instrumented Charpy test}

Depending on the mechanical behavior of materials subjected to dynamic loads at a specific temperature, the Charpy Instrumented test presents several types of load - time (or load - displacement) records, Figure 3. These charts show the load associated with the main events of these fracture processes, both in cases without plastic deformation (LEFM) or when there is some (restricted) plastic deformation (EPFM).

The areas under these curves are related to the fracture energy associated with the events marked on the load-time curve. This allows obtaining the quantities of partial energies associated with each of the fracture events, as well as the total energy for the rupture of the sample. These data from the curves of the Charpy Instrumented test (Figure 3), complemented with the fractographic analyzes of the surfaces of the fractured samples, allow to associate with these curves the processes of initiation, propagation and end of the fracture, and thus, highlight the microstructural characteristics of the material that control its fracture toughness.

In the Charpy Instrumented test, the load signal can present, especially in the elastic portion, a strong "oscillation", which can hinder or even prevent the indication of the loads associated with the main events, such as the general yield load $\left(\mathrm{P}_{\mathrm{Gy}}\right)$ and maximum load $\left(\mathrm{P}_{\mathrm{m}}\right)$. This disturbance in the load signal is due to the effects of vibration resulting from the contact, by impact, of the striker with the sample. This vibration effect is also accentuated in the case of brittle materials tested at low temperatures, when the fracture time is very short, and in some cases, when the sample is improperly positioned on the support base. There is bibliography 


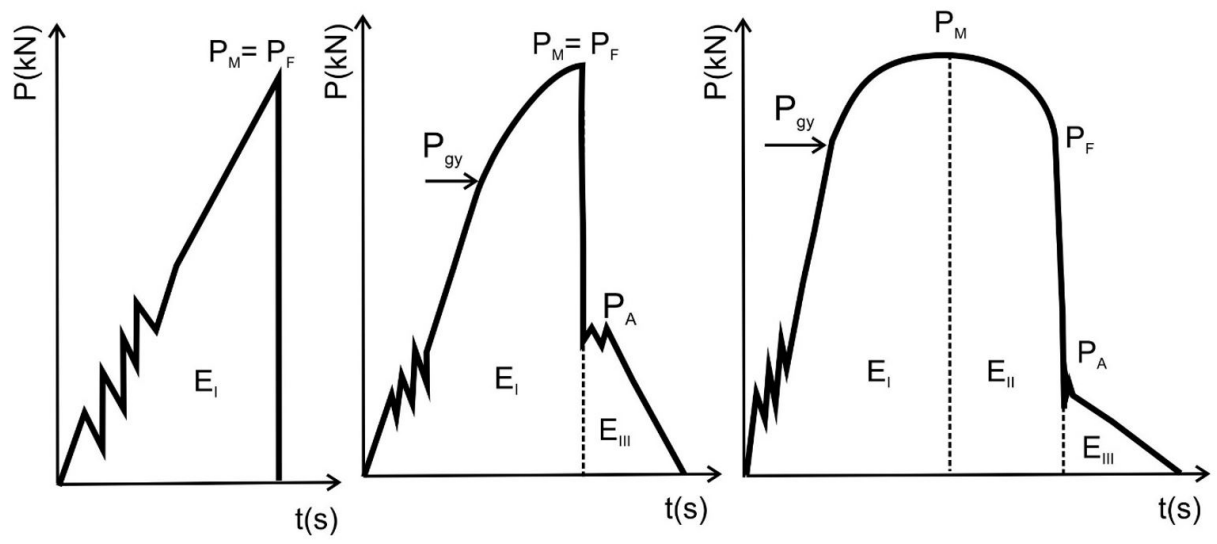

Figure 3. Instrumented Charpy test: load - time curves.

referring to studies related to the vibration modes on impact test system, and how these vibrations interfere with the load cell signal of the impact striker, which may compromise the load measurements in the tests [65-69].

To minimize fluctuations in the load signal, there is an indication of the use of filters in the processing of this signal. The condition of using these filters will be determined from the calculation of a parameter $(\tau)$ related to the oscillation period of the load-time signal [23]. The use of these filters must be done in a controlled way so that the curve is not "depressed", which would result in false load values.

A very efficient way to reduce oscillations is by adjusting the initial impact velocity $\left(\mathrm{V}_{\mathrm{o}}\right)$, associated with the initial pendulum height $\left(\mathrm{h}_{\mathrm{o}}\right),[23,65]$ :

$$
V_{o}=\sqrt{2 g h_{o}}
$$

In turn, the height of the pendulum is the parameter for controlling the amount of energy $\left(\mathrm{E}_{\mathrm{o}}\right)$ supplied to fracture the sample, where $m$ is the effective mass of the pendulum.

$$
E_{o}=\frac{1}{2} m V_{o}^{2}
$$

Considering that the sample absorbs in its fracture process an amount of $E_{M}$ energy, it is necessary to specify a height for the pendulum that it satisfies the following relationship: $E_{\mathrm{o}} \geq 3 E_{\mathrm{M}}$, in order to guarantee the complete performance of the test and minimize the loading signal oscillations [23].

\section{Use of the instrumented charpy load and energy in $\mathbf{J}$ Integral and $\mathrm{K}$ Calculations}

\subsection{Energy calculations}

From the $(P-t)$ curve it is possible to calculate the value of the energy associated with specific events of testing $(E-t)$, so that

$$
E_{a}=V_{o} \int_{o}^{t_{i}} P d t
$$

This integral term corresponds to the area under the $\mathrm{P}$ - $\mathrm{t}$ curve, and $t_{i}$ is the time of the specific event. At fracture $\left(P_{P} t_{F}\right)$ the integrated energy is calculated from the equations:

$$
W_{F}=V_{o} \int_{o}^{t_{F}} P d t\left[1-\left(V_{0}^{t_{F}} \int_{o} P d t / 4 E_{o}\right)\right]
$$

The amount of total energy absorbed for fracturing a sample under impact $\left(\Delta E_{0}\right)$ can be calculated from Equation 4 , considering the total load-time curve [23], such that:

$$
\Delta E_{o}=E_{a}\left[1-\left(E_{a}\right) / 4 E_{o}\right]
$$

This measure of the total integrated energy $\left(\Delta E_{\mathrm{o}}\right)$ can be compared with the total energy value measured by the dial at impact equipment $\left(E_{\mathrm{t}}\right)$, which is a way of checking the equipment calibration.

However, in a more rigorous approach to the effective fracture energy of the sample, it is necessary to consider the energy correction due to the "compliance" of the system under impact, and thus correct the energy value calculated by Equation 4 .

In the case of intergranular brittle fracture/cleavage, under LEFM conditions, characterized in the graph in Figure 3a, the fracture initiation coincides with a sudden drop in load signal at maximum load, and thus $P_{\mathrm{M}}=P_{\mathrm{F}}, t_{\mathrm{M}}=t_{\mathrm{F}}$. The energy for fracture, $E_{\mathrm{M}}$, can be calculated directly from the maximum load value $\left(P_{\mathrm{M}}\right)$, but it is necessary to include compliance correction, such that [23]:

$$
E_{M}=\frac{C_{N D}\left(P_{M}^{2}\right)}{2 E B}
$$

Where $(B)$ is the thickness of the specimen, $(E)$ the modulus of elasticity of the material and $\left(C_{N D}\right)$ is the parameter of the dimensionless "compliance", function of the a/W ratio, being "a" the crack size and "W" height of the specimen. 
The $C_{N D}$ values are found in the literature for Charpy samples with different values of a/W [23].

When the fracture involves some plastic deformation, Figure $3 \mathrm{~b}, \mathrm{c}$, the critical fracture is defined by the sharp drop of the load signal $\left(P_{\mathrm{M}}\right)$ after the general yield event $\left(P_{G y}\right)$.

The $(P-t)$ and $(E-t)$ signals are obtained simultaneously (Figure 1), so these curves provide the values of $\mathrm{P}_{\mathrm{M}}$ and $\mathrm{W}_{\mathrm{M}}$ for a reference time $t_{\mathrm{F}}=t_{\mathrm{M}}$, and the following equation is proposed for the calculation of the actual fracture energy $\left(E_{\mathrm{M}}\right)$ :

$$
E_{M}=W_{F}-\left\{\left(P_{M}^{2} / 2\right)\left[C_{T}-\left(C_{N D} / E B\right)\right]\right\}
$$

Where $C_{T}$ is the total "compliance" of the system associated with the general yield event $\left(P_{G y}\right)$ and corrected by the decrease in velocity due to this yield, such that $C_{T}$ can be calculated by Equation 8 , with $t_{G y}$ being the time associated with that event, and the other terms previously defined.

$$
C_{T}=\left(v_{o} t_{G y} / P_{G y}\right)-\left(v_{o}^{2} t_{G y}^{2} / 8 E_{o}\right)
$$

\subsection{Dynamic J Integral toughness measurement}

Considering that the fracture event corresponds to the maximum load $P_{\mathrm{M}}$, which is associated with the $E_{\mathrm{M}}$ energy value (Equations 6 or 7), the dynamic fracture toughness $J_{I d}$ can be calculated by [23]:

$$
J_{I d}=\frac{2 E_{M}}{B(W-a)}
$$

In its turn

$$
K_{J d}=\sqrt{E^{\prime} J_{I d}}
$$

Where $E^{\prime}=E /\left(1-v^{2}\right)$ in plane strain and $E^{\prime}=E$ in plane stress, $E$ Young's modulus of the elasticity and $v$ is Poisson's ratio.

\subsection{Compliance changing rate method}

For Charpy Instrumented tests in which the material presents plastic deformation and stable crack growth, it is possible to identify in the "load - displacement" curve the values of general yield load (PGy) and maximum load (PM). However, the value of the fracture initiation load $(\mathrm{Pi})$ is not identified. A method used to determine Pi is through the compliance rate curve $[70,71]$ is shown in Figure 4.

From the $P_{i}$ value, the dynamic fracture toughness $\mathrm{J}_{\mathrm{Id}}$ can be calculated by Equation 9, where $E_{M}$ corresponds to the energy for stable fracture initiation calculated from Equation 7, replacing $P_{M}$ with $P_{i}$, which was obtained by the compliance changing method [71].

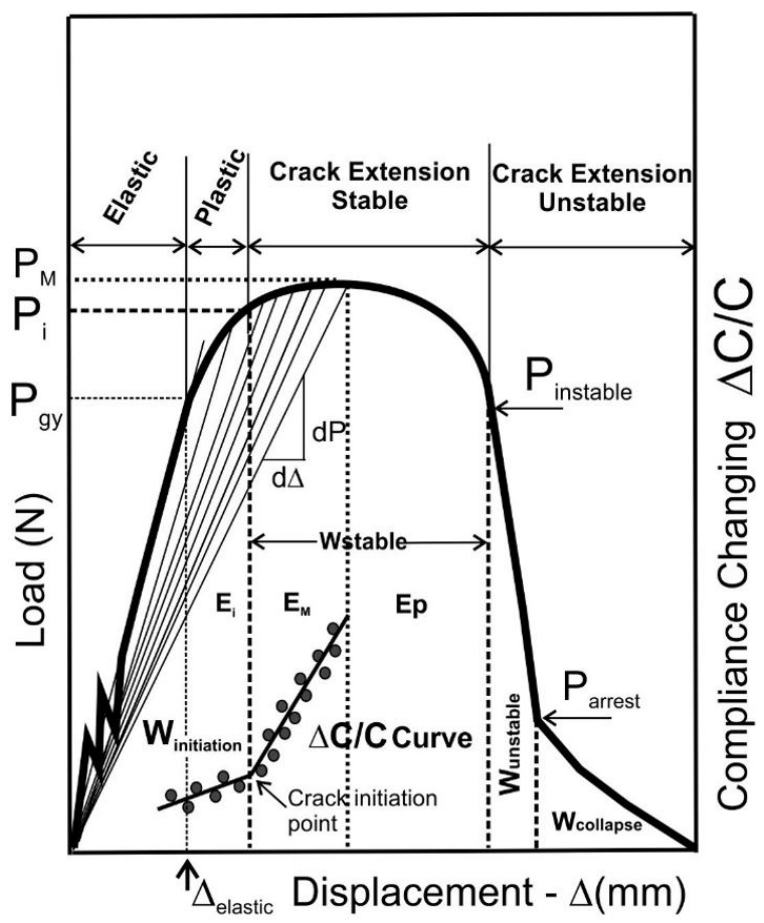

Figure 4. Load - Displacement and Load - Compliance Changing curves.

\section{Determination of fracture toughness from metallographic and fractographic analyzes}

\subsection{Stretch zone width method}

In elasto-plastic fracture conditions, after a certain load value, a stretch zone is formed in front of the crack. The local stress and strain result in a region of shear, and thus the crack tip is rounded and evolves to the formation of this stretch zone, which stabilizes with the beginning of the crack advance $[63,70]$. This region is perfectly identified in the fractographic analyzes of the sample's fracture surfaces (Figure 5).

From the measurement of the width of the stretch zone it is possible to calculate the value of $J_{I d}$, according to Equation 11 [70].

$$
J_{I d}=K \cdot \sqrt{2} \cdot \sigma_{y d} \cdot S Z W_{c}
$$

where $K$ is the constraint factor, relates to the stress-strain state at the crack tip, and depends on the sample's geometric factors and the material's mechanical characteristics, and calculated as follows

$$
K=\frac{1}{0,54(1+n)} \frac{2}{\sqrt{3}}\left[(1-\vartheta)(1+n) \frac{\sigma_{y d}}{n \cdot E}\right]^{-n}
$$

The $\sigma_{\mathrm{yd}}$ is the value of the dynamic yield strength of the material calculated by $[23,70]$ :

$$
\sigma_{y d}=\frac{\alpha P_{g y} W}{B(W-a)^{2}}
$$



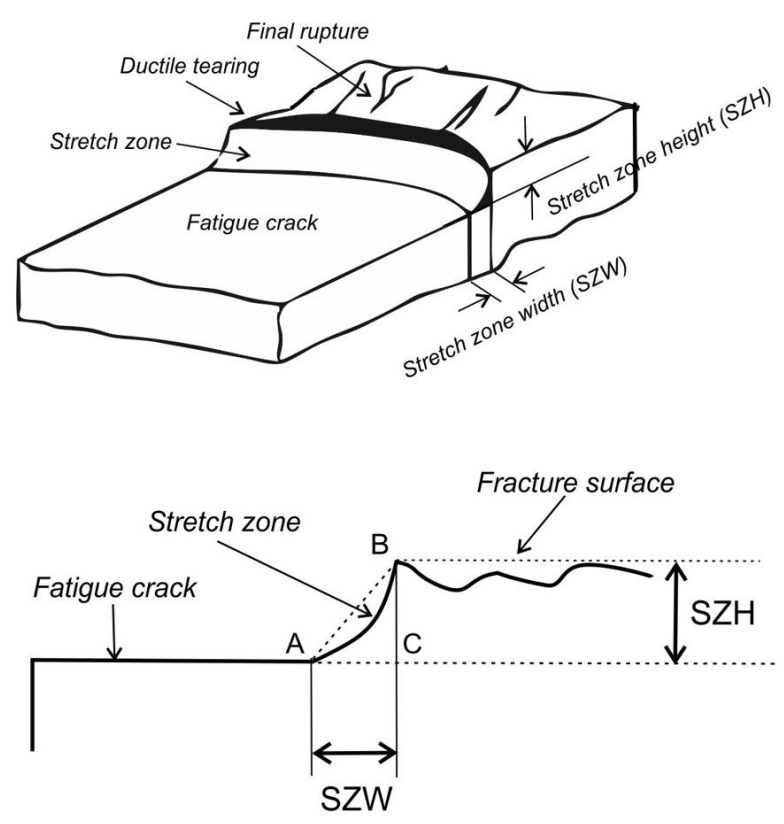

Figure 5. Stretch zone formation (SZW) on a fracture surface.

Where $P_{G y}$ is the general yield load, $B, W$ are the thickness and height, respectively, and a is the crack length of specimen (Charpy), and $\alpha=2.85$ (notch) or 2.99 (fatigue crack).

\subsection{Characteristic distance and microscopic ductility method for ductile fracture}

In an approach based on J-Integral, fracture initiation $\mathrm{J}_{\mathrm{i}}=\mathrm{J}_{\mathrm{Ic}}$ occurs when the local equivalent plastic strain $\left(\varepsilon_{\mathrm{p}}\right)$ exceeds the critical fracture strain (or ductility) $\varepsilon_{\mathrm{f}}{ }^{*}$, associated with a specific stress state, in a characteristic distance $l_{o}^{*}$ which is related to the average spacing between the particles that initiate the fracture process $\left(d_{p}\right)[16]$.

Therefore,

$$
J_{I c} \sim \sigma_{o} \varepsilon_{f}^{*} l_{o}^{*}
$$

or

$$
K_{I c} \equiv \sqrt{J_{I c} E^{\prime}} \sim \sqrt{E^{\prime} \sigma_{o} \varepsilon_{f}^{*} l_{o}^{*}}
$$

Where $\sigma_{0}$ is the flow stress.

Several equations are proposed for the calculation of $\varepsilon_{\mathrm{f}}{ }^{*}[72,73]$. However, the simplest approach to this ductility measure is presented by Thompson \& Ritchie $[16,74]$, such that:

$$
\varepsilon_{f}^{*} \simeq \ln \left(\frac{h}{D_{p}}\right)
$$

Where $D_{p}$ is the average diameter of the initiating particles and $h=$ average values of the height of the dimples associated with these particles.
In terms of the fraction (volume) of the particles $\left(f_{p}\right)$ and the parameter $M=h / w$, where $w$ is the average value of the width and $h$ the average value of the height of the dimples, we have:

$$
\varepsilon_{f}^{*} \simeq \frac{1}{3} \ln \left(\frac{M^{2}}{3 f_{p}}\right)
$$

And Equation 14 can be presented as follows:

$$
J_{I c} \sim \frac{\sigma_{o}}{3} \ln \left(\frac{M^{2}}{3 f_{p}}\right) l_{o}^{*}
$$

Equation 18 indicates that the $J_{I c}$ fracture toughness value can be estimated from microstructural parameters obtained through quantitative metallographic and fractographic analyzes, with a single fractured sample. In addition, it allows to associate the value of fracture toughness with the microstructural characteristics of the material such as the quantity $\left(f_{p}\right)$, average size $\left(D_{p}\right)$ and average spacing $\left(l_{o}^{*}\right)$ of the inclusions initiating the fracture process, and the plasticity of the material expressed by its microscopic ductility $\left(\varepsilon_{\mathrm{f}}{ }^{*}\right)$.

\section{Conclusion}

The Instrumented Charpy test is a very efficient method for assessing the fracture toughness of metallic materials. The small dimensions of the Charpy sample are of great importance for safety programs, as in the nuclear energy area, in view of the verification of the neutron irradiation phenomenon, which requires the placement of these samples to be irradiated in the reactors.

The preparation of notched specimens by machining processes is easy to perform, as well as the subsequent introduction of fatigue crack. Charpy tests are easy to perform for any temperature considering the test time is very short, enough to maintain the sample temperature during the test procedure.

From the registration of the "load-time" signal it is possible to verify the occurrence of the main events of the fracture process, therefore, an immediate qualitative analysis of the "ductile" or "brittle" behavior of the material under dynamic loading conditions, at a test temperature.

The use of the Instrumented Charpy test, presenting the absorbed energy measurements for each of the stages of the fracture process (initiation, stable and unstable growth and final rupture), allows the calculation of the fracture toughness parameters $\left(\mathrm{K}_{\mathrm{Jd}} / \mathrm{J}_{\mathrm{Id}}\right)$ from the initiation energy quantity. Thus, the advantage of using Instrumented Charpy is reinforced in relation to the use of the correlations equation [8] that propose these calculations from the total fracture energy value $\left(\mathrm{E}_{\mathrm{cv}}\right)$ obtained in the conventional Charpy test.

The possibility of obtaining the fracture toughness parameters $\left(\mathrm{K}_{\mathrm{Jd}}, \mathrm{J}_{\mathrm{Id}}\right)$, from specimens of reduced dimensions and under conditions of dynamic loading, is of great importance in the development and classification of materials, as well as to meet the requirements of structural projects in the various engineering areas. 


\section{References}

1 Hertzberg RW, Vinci RP, Hertzberg JL. Deformation and fracture mechanics of engineering materials. 5th ed. USA: John Wiley \& Sons; 2013. p. 499-502

2 Tóth L, Rossmanith HP, Siewert TAS. Historical background and development of the Charpy Test. European Structural Integrity Society. 2002;30:3-19.

3 Bent Russel S. Experiments with a new machine for testing materials by impact (reprint from 1898). In: Siewert TA, Manahan MP, editors. Pendulum impact testing: a century of progress. ASTM STP 1380. West Conshohocken, PA: ASTM International; 2002. p. 17-45.

4 Siewert TA, Manahan MP, McCowan CN, Marsh FJ, Ruth EA. The history and importance of impact testing. In: Siewert TA, Manahan MP, editors. Pendulum impact testing: a century of progress, ASTM STP 1380. West Conshohocken, PA: ASTM International; 2000. p. 3-16.

5 Charpy G. Essay on the metals impact bend test of notched bars (reprint from 1901), In: Siewert TA, Manahan MP, editors. Pendulum impact testing: a century of progress. ASTM STP 1380. West Conshohocken, PA: ASTM International; 2002. p. 46-69.

6 ASTM International. ASTM E-23 - Test Method for Notched Bar Impact Testing of Metallic Materials. Conshohocken, PA: ASTM International; 2020.

7 Tetelman AS, McEvily AJ Jr. Fracture of structural materials. USA: John Wiley \& Sons; 1967. p. 114-122.

8 Hertzberg RW, Vinci RP, Hertzberg JL. Deformation and fracture mechanics of engineering materials. 5th ed. USA: John Wiley \& Sons; 2013. p. 307-381.

9 Knott JF. Fundamentals of fracture mechanics. London: Butterworth; 1976.

10 Broek D. Elementary engineering fracture mechanics. 4th ed. USA: Kluwer Academic Publisher; 1986

11 ASTM International. ASTM E-399 - Test Method for Linear Elastic Plane-Strain Fracture Toughness of Metallic Materials. West Conshohocken, PA: ASTM International; 2020.

12 Anderson TL. Fracture mechanics: fundamentals and applications. 4th ed. USA: CRC Press; 2017

13 Hertzberg RW, Vinci RP, Hertzberg JL. Deformation and fracture mechanics of engineering materials 5th ed. USA: John Wiley \& Sons; 2013. p. 358-62.

14 ASTM International. ASTM E-1290 - Test Method for Crack-Tip Opening Displacement (CTOD) Fracture Toughness Measurement. West Conshohocken, PA: ASTM International; 2020.

15 ASTM International. ASTM E-1820 - Test Method for Measurement of Fracture Toughness. West Conshohocken, PA: ASTM International; 2020.

16 Ritchie RO, Thompson AW. On the macroscopic and microscopic analyses for crack initiation and crack growth toughness in ductile alloys. Metallurgical Transactions. A, Physical Metallurgy and Materials Science. 1985;6A:233247.

17 Pisarski HG. Application and verification of the SINTAP fracture toughness estimation procedure for welds and parente materials. FITNET; 1999. p. 1-15. TWI Report n. 88269/3-3/99.

18 Webster S, Bannister A. Structural integrity assessment procedure for Europe - of the SINTAP programme overview. Engineering Fracture Mechanics. 2000;67:481-514.

19 Hadley I. BS 7910:2013 - Guide to methods for assessing the acceptability of flows in metallic structures. International Journal of Pressure Vessels and Piping. 2000;165:263-269.

20 American Petroleum Institute. API 5L Specification for Line Pipe, 43th ed. USA: American Petroleum Institute; 2004.

21 International Organization for Standard. ISO 14556 - Int. Standard - Steel - Charpy V-notch pendulum impact test instrumented test method. Switzerland: International Organization for Standard; 2000.

22 ASTM International. ASTM E-2298 - Standard Test Method for Instrumented Impact Testing of Metallic Materials, West Conshohocken, PA: ASTM International; 2020.

23 Server WL. Impact three-point bend testing for notched and precracked specimens. Journal of Testing and Evaluation. 1978;6(1):29-34.

24 Kobayashi T. Development in the instrumented Impact test - computer aided instrumented impact testing system. In: François D, Pineau A, editors. From charpy to present impact testing. France: Elsevier Science Ltd; 2002. p. 165-172 
25 Sánches L, Gutiérrez-Solana F. Correlation between impact resistance and fracture toughness in aged duplex stainless steels. In: François D. Pineau A, editors. From charpy to present impact testing. France: Elsevier Science Ltd; 2002. p. 87-94

26 Alar Z, Mandic D, Dugorepec A, Sakoman M. Application of instrumented Charpy method in characterisation of materials. Interdisciplinary Description of Complex Systems. 2015;13(3):479-487.

27 Tronskar JP, Mannan MA, Lai MO. Correlation between quasi-static and dynamic crack resistance curves. Engineering Fracture Mechanics. 2002;70:1527-1542.

28 Viehring H, Boehmert J, Dzugan J. Use of instrumented Charpy impact tests for the determination of fracture toughness values. In: François D, Pineau A, editors. From Charpy to present impact testing. France: Elsevier Science Ltd; 2002. p. 245-252.

29 Yu M, Luo Z, Chao YJ. Correlations between Charpy V-notch impact energy and fracture toughness of nuclear reactor pressure vessel (RPV) steels. Engineering Fracture Mechanics. 2015;147:187-202.

30 Wallin K, Valo M, Rintamaa R, Torronen K, Ahlstrand R. Descriptive characteristics of different types of test for irradiation embrittlement. Nuclear Engineering and Design. 1995;159:69-80.

31 Ohtsuka N, Shindo Y, Makita A. Evolution of hydrogen embrittlement. European Physical Journal Web Conferences. Instr Charpy test, EPJ Web of Conferences, 2010;6(14004):1-7.

32 Schindler HJ, Kalkhof D, Tipping P, Sokolov M, Dean SW. Determination of transferable Lower-Bound Fracture toughness from small specimens. Journal of ASTM International. 2008;5(8):1-11.

33 Chaouadi R, Puzzolante JL. Procedure to estimate the crack resistance curve from the Instrumented Charpy V-Notched Impact Test. In: Proceedings of the 12th International Conference on Fracture; 2012; Ontario, Canada. Ontario: SCK CEN Publications; 2012. Vol. 1, p. 1-10.

34 Parrot A, Dahl A, Forget P, Marini B. Evaluation of fracture toughness from Instrumented Charpy impact test for a reactor pressure vessel steel using Local Approach to fracture. In: Proceedings of the Conference EMMC9, 2006; France. The Netherlands: EUROMECH; 2006. p. 1-7.

35 Tronskar JP, Mannan MA, Lai MO. Measurement of fracture initiation toughness and crack resistance in instrumented Charpy impact testing. Engineering Fracture Mechanics. 2002;69:321-338.

36 Holzmann M, Dlouhy I, Brumovsky M. Measurement of fracture toughness behaviour of Cr-Ni-Mo-V pressure vessel steel using pre-cracked Charpy specimens. International Journal of Pressure Vessels and Piping. 1999;76:591598.

37 Canonico DA, Stelzman WJ, Berggren RG, Nanstad RK. Use of instrumented charpy tests to determine onset of upper-shelf energy. Welding Research Supplement. 1981;5:85s-91s.

38 Lucon E, McCowan CN, Santoyo RL. Impact characterization of line pipe steels by means of standard, sub-size and miniaturized Charpy specimens. NIST Tech. Note. 1865;2015:1-56.

39 Alfitouri AO, Savas MA, Evcil A. Charpy Impact and tension tests of two pipeline materials at room and cryogenic temperatures. Int. Journal of Applied Engineering Research. 2018;13(17):13321-13334.

40 Hashemi SH. Apportion of Charpy energy in API 5L grade X70 pipeline steel. International Journal of Pressure Vessels and Piping. 2008;85(12):879-884.

41 Hashemi SH, Jalali MR. Experimental study of Charpy impact characteristics of high-strength spiral welded gas pipeline. In Proceedings of the 2006 International Pipeline Conference; IPC 2006; Alberta, Canada. USA: ASME; 2006. p. 57-63. Paper n. IPC-2006-10068.

42 Pereira LC, Silva CRM. Efeito do hidrogênio sobre o aço CORTEN. Rio de Janeiro: Pontifícia Universidade Católica do Rio de Janeiro; 1977. p. 1-72. Undergraduate Notes.

43 Pereira LC. Estudo da tenacidade a fratura dinâmica do aço AISI 4140 em vários estados microestruturais. [dissertação]. Rio de Janeiro: Pontifícia Universidade Católica do Rio de Janeiro; 1981.

44 Strohaecker TR. Influencia dos tratamentos térmicos sobre a tenacidade de um aço ABNT 4340 [dissertação]. Universidade Federal do Rio Grande do Sul; 1980.

45 Server WL, Wullaert RA, Sheckherd JW. Verification of the epri dynamic fracture toughness testing procedures. Sunnyvale: Effects Technology Inc.; 1975. Topical Report 75-42.

46 Saxton HJ, Ireland DR, Server WL. Analysis and control of inertial effects during instrumented impact testing. In: DeSisto TS. ASTM STP 563: instrumented impact testing. West Conshohocken, PA: ASTM International; 1973. 
47 Zackay WE, Parker RD, Wood WE. Influence of some microstructural features on the fracture toughness of high strength steels. In: Proceedings of the Third International Conference on the Strength of Metals and Alloys; 1973 August 20-25; Cambridge, England. Institute of Metals, London, August 1973. p. 1-14

48 Ritchie, RO, Horn, RM. Further considerations on the inconsistency in toughness evaluation of AISI 4340 steel austenitized at increasing temperatures. Metallurgical Transactions A. 1978;9:331-341.

49 Firrao D, Begley JA, Silva, RR, De Benedetti. The influence of notch root radius and austenitizing temperature on fracture apparence of as-quenched Charpy-V type AISI 4340 steel specimens. Metallurgical Transactions A. 1982;13:1003-1013.

50 Taylor D. The theory of critical distance: a new perspective in fracture mechanics. UK: Elsevier; 2007.

51 Horn RM, Ritchie RO. Mechanisms of tempered martensite embrittlement in low alloy steels. Metallurgical Transactions A. 1978;9:1039-1053.

52 Darwish FAI, Pereira LC, Gatts C, Graça MLA. On the tempered martensite embrittlement in AISI 4140 low alloy steel. Materials Science and Engineering. 1991;132:L5-L9.

53 Reguly A, Matlock DK, Krauss G. Grain boundary features at an intergranular fracture of a martensitic AISI 5160 steel. Acta Micros. 1998;7(19):285-288.

54 Krauss G. Steels - processing, structure and performance. West Conshohocken, PA: ASTM International; 2005. p. 383-410.

55 Ritchie RO, Knott JF, Rice JR. On the relationship between critical tensile stress and fracture toughness in mild steel. Journal of the Mechanics and Physics of Solids. 1973;21:395-410.

56 Tetelman AS, Wilshaw TR, Rau CA. The critical tensile stress for cleavage. International Journal of Fracture Mechanics. 1968;4:147-156.

57 Thompson AW, Knott JF. Micromechanisms of brittle fracture. Metallurgical Transactions. A, Physical Metallurgy and Materials Science. 1993;24:523-534.

58 Evans AG. Statistical aspects of cleavage fracture in steel. Metallurgical Transactions. A, Physical Metallurgy and Materials Science. 1983;14:1349-1355.

59 Chen JH, Cao R. Micromechanism of cleavage fracture os metals: a comprehensive microphysical model for cleavage cracking in metals, London: Elsevier; 2015.

60 Pugh SF. An introduction to grain boundary fracture in metals, London: The Institute of Metals; 1991.

61 Thomason PF. Ductile fracture of metals. Oxford: Pergamon Press; 1990.

62 Graça MLA. Micromecanismos de iniciação da fratura em amostras entalhadas [tese]. Guaratinguetá: Universidade Estadual Paulista "Júlio de Mesquita Filho"; 2002.

63 Pineau A. Modeling ductile to brittle fracture transition in steels - micromechanical and physical challenges. International Journal of Fracture. 2008;150:129-156.

64 Ireland DR. Procedures and Problems Associated with Reliable Control of the Instrumented Impact Test. In: DeSisto TS. STP 563: instrumented impact testing. West Conshohocken, PA: ASTM International; 1973. p. 3-29.

65 Landrein P, Lorriot T, Guillaumat L. Influence of some test parameters on specimen loading determination methods in instrumented Charpy impact test. Engineering Fracture Mechanics. 2001;68:1631-1645.

66 Shterenlikht A, Hashemi SH, Yates JR, Howard IC, Andrews RM. Assessment of na instrumented Charpy impact machine. International Journal of Fracture. 2005;132:81-97.

67 Strohaecker TR, Djongue W. Influência dos tratamentos térmicos sobre a tenacidade de um aço SAE 4340. Metalurgia - ABM; 1981;37(285):457-461.

68 Morita S, Otani M, Kobayashi T. Problems related to the measurement of load signal in the instrumented Cahrpy impact test, In: François D, Pineau A, editors. From Charpy to present impact testing. France: Elsevier Science Ltd; 2002. p. 213-220.

69 Xinping Z, Yaowu S. Comparative studies of several methods to determine the dynamic fracture toughness of a nuclear pressure vessel steel A508 CL3 with Charpy-size specimen. International Journal of Fracture. 1996;81:195204.

70 Lin Y, Yu Q, Pan J, Duan F, Ritchie RO, Li Y. On the impact toughness of gradient-structured metals. Acta Materialia. 2020;193:125-137. 
Use of instrumented charpy testing on the fracture toughness characterization of metallic materials

71 Rice JR, Tracey DM. On the ductile enlargement of voids in triaxial stress fields. Journal of the Mechanics and Physics of Solids. 1969;17:201-217.

72 McClintock FA. A criterion for ductile fracture by the growth of holes. Journal of Applied Mechanics. 1968;35:363371.

73 Thompson AW, Ashby MF. Fracture surface micro-roughness. Scripta Metallurgica. 1984;18:127-130.

74 Thompson AW. The relation between changes in ductility and in ductile fracture topography: control by microvoid nucleation. Acta Metallurgica. 1983;31(10):1517-1523.

Received: 18 Aug. 2020

Accepted: 23 Nov. 2020 